\title{
Time-dependent selected reaction monitoring-based GC-MS/MS method for estimation of genotoxic impurities in new antibacterial agent: alalevonadifloxacin mesylate
}

\author{
Vinod K. Ahirrao* (D), Rajiv A. Jadhav, Vipul P. Rane, Harshal R. Bhamare and Ravindra D. Yeole
}

\begin{abstract}
Alalevonadifloxacin mesylate (ALA), pro-drug of levonadifloxacin is a new antibiotic approved in India to treat infections caused by Gram-positive bacteria. Alkyl mesylates (AMs) are known genotoxic impurities (GTI's) formed in drug substances isolated as mesylate salts. Time-dependent selected reaction monitoring (t-SRM)-based gas chromatography tandem mass spectrometry (GC-MS/MS) method has been developed for trace estimation of AMs, namely, methyl methane sulfonate (MMS), ethyl methane sulfonate (EMS) and isopropyl methane sulfonate (IMS) in ALA. Liquid-liquid extraction (LLE) procedure using dichloromethane (DCM) as an extracting solvent was employed to extract AMs from the drug substance. Automatic selective reaction monitoring (auto-SRM) tool was applied to identify the most intense SRM pair of the ions to achieve the highest sensitivity. The method was validated in terms of specificity, linearity, sensitivity, precision, and accuracy. The limit of quantitation (LOQ) for the MMS, EMS and IMS were 5, 10, and $20 \mathrm{ng} / \mathrm{g}$ of ALA, respectively. For all analytes, the correlation coefficient (R) were greater than 0.9975 in the concentration range of 3.0-260 ng/mL. Mean recovery of all analytes was in the range of 91.77 to $97.65 \%$.
\end{abstract}

Keywords: Alalevonadifloxacin, GC-MS/MS, Time-dependent SRM, Alkyl mesylates

\section{Introduction}

A broad group of fluoroquinolones and quinolones is used as an antibacterial agent in clinics. Alalevonadifloxacin (ALA, WCK 2349) is a mesylate salt of L-alanine ester pro-drug of levonadifloxacin. Chemically, it is S-(-)-9-fluoro-8-(4-L-alaninyloxypiperidin-1-yl)-5-methyl-6,7-dihydro-1-oxo- $1 \mathrm{H}, \quad 5 \mathrm{H}-$ benzo-[i, j]-quinolizine-2-carboxylic acid methane sulfonic acid salt (Patel et al. 2012). The chemical structure of ALA is shown in Fig. 1. ALA has completed phase I study in US (ClinicalTrials.gov Identifier: NCT02217930) and phase III study in India for the treatment of skin and skin structure infections (Chugh et al. 2015; Niu et al. 2015; Chugh et al. 2016;

\footnotetext{
* Correspondence: vahirrao@wockhardt.com

Wockhardt Research Centre, D-4, MIDC, Chikalthana, Aurangabad 431006, India
}

Rodvold et al. 2018; Mason et al. 2019). Very recently, a marapproval has been issued by the Drug Controller Genpropanol as solvents at various stages of synthesis and during purification. Possibility of undesired reactions between the to genetic mutations causing cancer. These impurities induce genetic mutations or chromosomal abnormalities in bacterial and mammalian cell systems, as well as in vitro salmonella reverse mutation (Ames) and micronucleus 
<smiles>C[C@H](N)C(=O)OC1CCN(c2c(F)cc3c(=O)c(C(=O)O)cn4c3c2CC[C@H]4C)CC1</smiles>

ALA
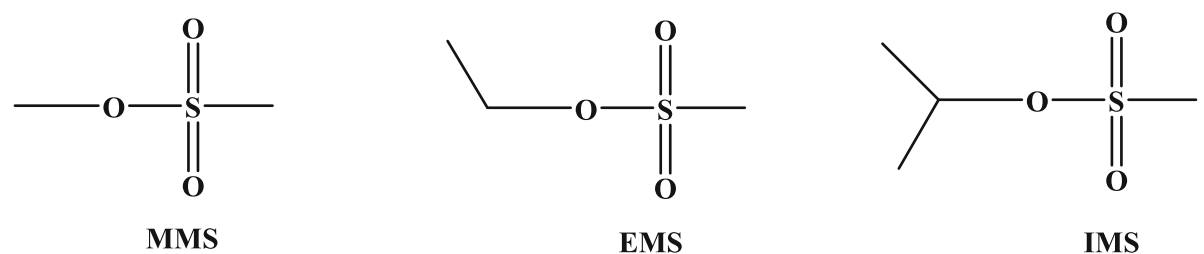

Fig. 1 Chemical structure of ALA (alalevonadifloxacin mesylate), MMS (methyl methane sulfonate), EMS (ethyl methane sulfonate), and IMS (isopropyl methane sulfonate)

tests. ICH guideline M7 (R1) adopted a staged "threshold of toxicological concern (TTC)" concept based on the daily dose and duration of the treatment. Working Party, which has been appointed in 2008 by the European Pharmacopoeia Commission, has elaborated five general chapters on different sulfonates, which have been published in the European Pharmacopoeia Supplement 8.7 that came into force on 1 April 2016 [Muller et al. 2006; EMEA guideline on genotoxic impurities 2006; Recommnended approaches on genotoxic and carcinogenic impurities by CDER 2008; Teasdale 2011; ICH guideline M7(R1) 2017).

Literature reveals several chromatographic approaches, including LC-MS and GC-MS for the determination of genotoxic impurities in pharmaceutical products. Alkylsulfonates in capacitabine and imatinib methanesulfonate were estimated using GC-MS/MS-based method (Liu et al. 2019). AMs in lamivudine were determined by using GCMS in selected ion monitoring (SIM) mode (Ramana et al. 2012). AMs in doxazosin mesylate were determined by using GC-MS in SIM mode (Sitaram et al. 2011). MMS and EMS were estimated in imatinib mesylate by GC-MS (Ramakrishna et al. 2008). Solid phase micro-extractionbased sample preparation was employed for the estimation of AMs in some active pharmaceutical ingredients using GC-MS (Colon and Richoll 2005). Trace determination of alkyl sulfonates by derivatization followed by GC-head space analysis was reported (Liu et al. 2018). Derivatization-based LC-MS method was applied to achieve the sensitivity for estimation of alkyl sulfonates (An et al. 2008). MMS and EMS were determined in emtricitabine by LC-MS/MS using electrospray ionization (Kakadiya et al. 2011). Sulfonate esters in imatinib mesylate and vinpocetine were estimated by LC-MS/MS (Guo et al. 2014). Simultaneous determination of mesylates and besylates was carried out by direct injection on GC-MS (Wollein and Schramek 2012). Alkylating agents were estimated using derivatization and headspace GC-MS methodology (Alzaga et al. 2007).

Use of t-SRM acquisition in GC-MS/MS analysis has been proved to be more sensitive and selective than the traditional SIM method. It reduces the matrix effects, which often impact the recovery and sensitivity of the method (Introduction of Auto SRM, Thermo fisher scientific 2012; Dobbeleer et al. 2018).

Herein, we describe t-SRM-based GC-MS/MS method development for quantification of AMs (MMS, EMS and IMS) in new drug substance ALA and its validation. An efficient procedure for extraction of genotoxic impurities from the water soluble drug substance is also elaborated.

\section{Material and methods}

Chemicals and reagents

MMS and EMS were purchased from Spectrochem Pvt Ltd. (India). IMS was purchased from Across Organics (USA). Chlorobenzene was procured from Qualigen fine chemicals (India). ALA was synthesized in-house at the Wockhardt Research Centre, India. HPLC grade dichloromethane (DCM) was supplied by Avantor (India). Water passed through Milli-Q (Millipore, USA) was used during analysis. Rtx- 6.24 column $30 \mathrm{~m} \times 0.32 \mathrm{~mm}$ I.D. with $1.8 \mu \mathrm{m}$ film thickness (Restec Technologies, USA) was used for GC-MS/MS studies.

\section{GC-MS/MS conditions}

The GC-MS/MS analysis was performed on Trace 1300 gas chromatograph coupled with TSQ 8000 Evo triple 
quadrupole mass spectrometer as detector and AI 1310 auto liquid sampler (Thermo fisher Scientific, USA). Rtx-624, $30 \mathrm{~m} \times 0.32 \mathrm{~mm}$ I.D. with $1.8 \mu \mathrm{m}$ film thickness column was used for analysis. The initial oven temperature was set at $80{ }^{\circ} \mathrm{C}$ and held for $1 \mathrm{~min}$, raised to $150{ }^{\circ} \mathrm{C}$ at $15{ }^{\circ} \mathrm{C} / \mathrm{min}$, for $4 \mathrm{~min}$. High-purity helium (purity 99.999\%) was used as the carrier gas at a constant flow rate of $1.5 \mathrm{~mL} / \mathrm{min}$. Injector port temperature was set at $180{ }^{\circ} \mathrm{C}$. Injection volume was $2 \mu \mathrm{L}$. Injections were made in split mode with split ratio 10:1. Runtime for the analysis was 9.67 minute. Data acquisition and processing was performed using Chromeleon 7.2 SR5 chromatographic software.

The mass spectrometer was operated in positive electron impact ionization $(70 \mathrm{eV})$ mode and data was acquired using t-SRM function for quantitative analysis. The MS transfer line and ion source temperature were set at $250{ }^{\circ} \mathrm{C}$ and $200{ }^{\circ} \mathrm{C}$, respectively. Quadrupole Q1 and Q3 were set at unit resolution with scanning speed $20 \mathrm{~Hz} / \mathrm{s}$ for $0.3 \mathrm{~s}$. Analyte-dependent MS parameters are depicted in Table 1.

\section{Preparation of analytical solutions and extraction procedure}

Chlorobenzene was used as an internal standard (IS). IS was dissolved in DCM at a concentration of $40 \mathrm{ng} / \mathrm{mL}$. This solution was used as an extraction solvent. Standard stock solution of MMS, EMS, and IMS was prepared at concentration of $50 \mathrm{ng} / \mathrm{mL}$ in an extraction solvent. Test solution was prepared by extracting aqueous solution of ALA (100 mg in $0.5 \mathrm{~mL}$ ) using $1 \mathrm{~mL}$ of an extraction solvent. The mixture was vortexed for $30 \mathrm{~s}$ and allowed to separate the two layers. Lower layer (DCM layer) was used for analysis. Standard solution was prepared by adding 0.5 $\mathrm{mL}$ of water into $1 \mathrm{~mL}$ of standard stock solution and processed in similar way. Area ratio of individual analyte peak and IS peak were considered for quantitation of

Table 1 Analyte-dependent MS parameters for SRM pairs

\begin{tabular}{lllll}
\hline Parameter & Chlorobenzene & MMS & EMS & IMS \\
\hline Retention time (min) & 4.83 & 5.79 & 6.71 & 7.15 \\
RT window (min) & 0.6 & 0.5 & 0.5 & 0.5 \\
Polarity & Positive & Positive & Positive & Positive \\
Quantifier ion pair & & & & \\
Precursor ion mass & 112 & 80 & 109 & 123 \\
Product ion mass & 77.1 & 65 & 79 & 79 \\
Collision energy & 15 & 5 & 5 & 10 \\
Qualifier ion pair & & & & \\
Precursor ion mass & 77.1 & 79.1 & 79 & 79 \\
Product ion mass & 51.1 & 75.6 & 78.3 & 78 \\
Collision energy & 10 & 50 & 5 & 5 \\
\hline
\end{tabular}

AMs. During extraction method optimization, each experiment was performed in triplicate.

\section{Method validation}

Method was validated as per the ICH guideline Q2(R1) (ICH 2005). System precision was determined by analyzing standard solution six times and RSD of peak area ratio was reported, RSD of $\leq 15 \%$ was considered as acceptable. Method precision was evaluated by analyzing six individual test preparations. RSD of \% content of MMS, EMS and IMS were determined. Intermediate precision was determined by performing experiment by different analyst using different column. RSD of $\leq 15 \%$ was an acceptable limit. Limit of detection (LOD) and limit of quantitation (LOQ) were determined by "signal to noise ratio $(\mathrm{S} / \mathrm{N})$ " method. Standard solutions in the low range of concentrations were prepared, extracted, analyzed, and $\mathrm{S} / \mathrm{N}$ was determined. $\mathrm{S} / \mathrm{N}$ of 3:1 and 10:1 was considered acceptable for LOD and LOQ respectively. Six replicate measurements were performed at the determined LOD and LOQ concentrations; RSD of $\leq$ $33 \%$ and $\leq 15 \%$, respectively, was considered as acceptable. Accuracy of the method was determined by standard addition method. Accuracy was determined at three levels viz. 50,100 , and $150 \%$ of the proposed specification limit $(0.5 \mu \mathrm{g} / \mathrm{g})$. Method was considered as an accurate when the mean recoveries obtained are in the range of 80 to $120 \%$. Robustness of the method was evaluated by purposely varying the chromatographic conditions like carrier gas flow rate, oven temperature, and injector temperature. The standard solution was analyzed in six replicates at each variable condition, and impact on the chromatographic separation and precision of the determination was evaluated.

\section{Results and discussion \\ Method development Chromatographic separation}

Column selection and chromatographic parameters optimization was carried out using GC with MS as a detector. During method development variety of stationary phase columns like DB-1, DB-624, Rtx-624, and DB-5 were evaluated in terms of the analyte peak resolution, column efficiency and peak shape. DB-5 and DB-1 column showed unsymmetrical peak shapes. DB-624 column also showed unsymmetrical peak shape and low column efficiency (less sensitivity) for IMS. Rtx-624 (cross bonded 6\% cyanoproylphenyl $94 \%$ dimethyl polysiloxane) column showed better performance in terms of symmetrical peak shape, resolution and sensitivity. Hence Rtx-624 column was chosen for conducting further experiments. Comparative total ion chromatograms acquired on these columns are presented in Fig. 2 and the chromatographic performance data is shown in Table 2 . 


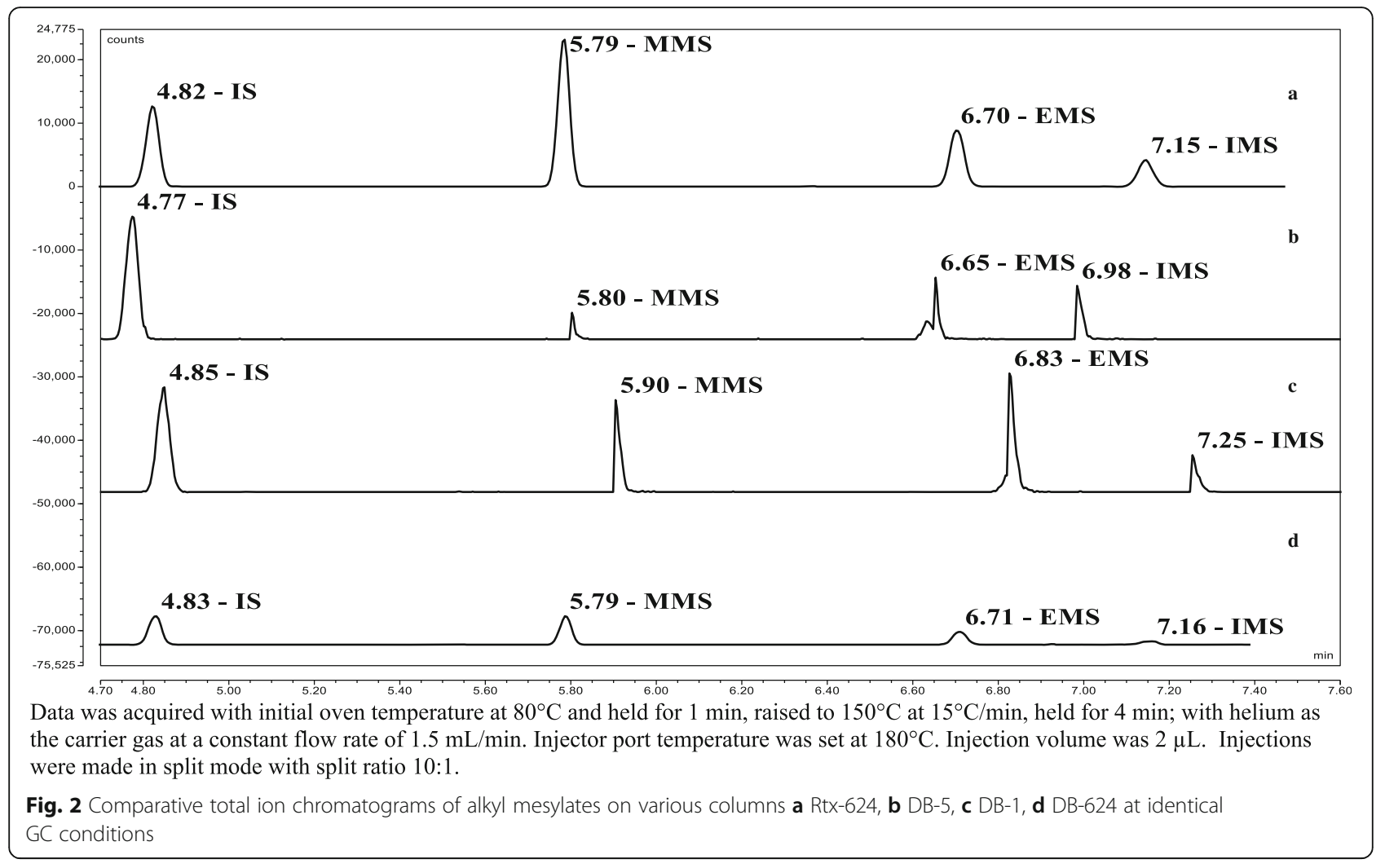

Table 2 Chromatographic performance data

\begin{tabular}{lllllll}
\hline Column & Parameter & Chlorobenzene & MMS & EMS & IMS & Remark \\
\hline Rtx-624 & Retention time (min) & 4.83 & 5.79 & 6.71 & 7.15 & Ideal peak shape \\
& No. of theoretical plates & 101708 & 190290 & 210354 & 148517 & \\
& Tailing factor & 0.96 & 1.07 & 0.98 & 0.97 & \\
& Resolution & - & 16.91 & 16.58 & 6.63 & \\
DB-5 & Retention time (min) & 4.77 & 5.80 & 6.65 & 6.98 & Unsymmetrical peaks \\
& No. of theoretical plates & 80486 & 75084 & 135201 & 108511 & \\
& Tailing factor & 1.01 & 2.74 & 0.74 & 3.38 & \\
& Resolution & - & 14.8 & 10.9 & 5.8 & \\
DB-1 & Retention time (min) & 4.85 & 5.90 & 6.83 & 7.25 & Unsymmetrical peaks \\
& No. of theoretical plates & 110932 & 92035 & 157181 & 105789 & \\
& Tailing factor & 0.94 & 2.81 & 1.24 & 3.55 & \\
& Resolution & - & 15.3 & 15.8 & 6.1 & \\
DB-624 & Retention time (min) & 4.83 & 5.79 & 6.71 & 7.16 & Unsymmetrical peaks and low sensitivity for IMS \\
& No. of theoretical plates & 117254 & 191748 & 196673 & 62078 & \\
& Tailing factor & 0.90 & 1.04 & 0.95 & 0.76 & \\
& Resolution & - & 17.48 & 16.32 & 5.11 & \\
\hline
\end{tabular}




\section{Optimization of extraction solvent and procedure}

Selection of an extraction solvent was a critical step in achieving the recovery of the AMs from the drug substance. ALA is freely soluble in water and very slightly soluble or practically insoluble in organic solvents like methanol, DCM, ethanol, and n-hexane. In contrast, MMS, EMS, and IMS are freely soluble in organic solvents like methanol, DCM, and n-hexanes and practically insoluble in water. The difference in the solubility of the drug substance and AMs was ideal situation for the application of LLE procedure. LLE procedure made the sample devoid of matrix hence improved the life of GC column; it also helped in improving sensitivity.

ALA $(100 \mathrm{mg})$ was dissolved in minimum quantity $(0.5 \mathrm{~mL})$ of water and attempts were made to extract AMs using various water immiscible solvents like nhexane, ethyl acetate, toluene, chloroform, DCM, and methyl tertiary butyl ether. Extraction efficiency was determined by standard addition method. AMs were spiked in ALA at $0.25,0.50$, and $0.75 \mu \mathrm{g} / \mathrm{g}$ in triplicate and extracted with respective solvents. Extraction efficiency was calculated by using following equation

$$
\begin{gathered}
\text { Extraction efficiency (mean recovery, } n=3 \text { ) } \\
=\frac{\text { Found amount of AMs in ALA } * 100}{}
\end{gathered}
$$

In ethyl acetate, mean recovery of AMs was in the range of 63.11 to $74.17 \%$, in toluene, it was 76.77 to $79.51 \%$, in $\mathrm{n}$-Hexane and methyl tertiary butyl ether, mean recoveries were much below, i.e., < $58 \%$. Mean recovery of AMs in halogenated solvents viz dichloromethane and chloroform were in the range of 92.69 to $96.18 \%$ and 72.25 to $77.01 \%$ respectively. Thus maximum recovery was achieved in DCM as a solvent. This might be due to different solubility of AMs in the tested organic solvents. The polarity index of the tested solvents is chloroform (4.1) > dichloromethane (3.92) > methyl tertiary butyl ether (2.4) > toluene (2.4) (data obtained from Polarity index of solvents https://macro.lsu.edu). Extraction efficiency data is presented in Table 3.

Table 3 Extraction efficiency of various extraction solvents

\begin{tabular}{lllll}
\hline \multirow{2}{*}{$\begin{array}{l}\text { Matrix } \\
\text { solvent }\end{array}$} & Extraction solvent & \multicolumn{3}{l}{ Recovery (\%) } \\
\cline { 3 - 5 } & & MMS & EMS & IMS \\
\hline Water & Ethyl acetate & 63.11 & 65.02 & 74.17 \\
Water & Toluene & 79.51 & 77.71 & 76.77 \\
Water & n-Hexane & 56.55 & 52.13 & 55.93 \\
Water & Dichloromethane & $\mathbf{9 2 . 6 9}$ & $\mathbf{9 5 . 1 1}$ & $\mathbf{9 6 . 1 8}$ \\
Water & Chloroform & 72.25 & 77.01 & 73.44 \\
Water & Methyl tertiary butyl ether & 52.11 & 57.85 & 58.07 \\
\hline
\end{tabular}

\section{Auto-SRM optimization}

Manual SRM method development is time-consuming, it involves selection of one or two precursor ions for each analyte, and subsequently collision energy needs to be optimized to obtain maximum response for product ions for detection. In auto-SRM method development the MS software systematically determines the intense precursor ion and product ion pairs. For auto-SRM method development, solution containing MMS, EMS, and IMS at concentration of $1000 \mathrm{ng} / \mathrm{mL}$ was used. Optimization of auto-SRM method involves three step procedure. In first step, precursor ions were identified by acquiring the data in full scan mode. Due to high energy electron ionization, 3 to 4 precursor ions were formed for each analyte. The mass spectra of MMS, EMS, IMS, and IS are provided in supplementary file S1. In second step, all the precursors were sent for possible product ion formation. SRM pairs of the most intense precursors and product ions were created. In third step, collision induced fragmentation was optimized by ramping the collision energy.

For MMS, quantifier SRM pair was $80>65.1$ and qualifier SRM pair was $79.1>75.6$. The MMS possess mass of $110 \mathrm{Da}$, loss of $-\mathrm{OCH}_{2}$ with transfer of hydrogen generates ion of $m / z$ 80. From $m / z$ 80, loss of methyl produces $m / z$ 65.1. Loss of methoxy from parent molecule $(\mathrm{m} / z 110)$ gives rise to the fragment ion of $\mathrm{m} / \mathrm{z}$ 79.1, which sub-sequentially undergoes carbene formation having $\mathrm{m} / \mathrm{z} 76.1$.

For EMS, quantifier SRM pair was $109>79$ and qualifier SRM pair was $79>78.3$. EMS possess mass of 124 $\mathrm{Da}$, loss of methyl from EMS generates ion having $\mathrm{m} / \mathrm{z}$ 109. From $m / z 109$, loss of $-\mathrm{OCH}_{2}$ produces ion of $m / z$ 79. This ion further fragments to $m / z 78.3$ with loss of hydrogen.

For IMS, quantifier SRM pair was $123>79$ and qualifier SRM pair was $79>78$. IMS possess mass of $138 \mathrm{Da}$, loss of methyl from IMS leads to give fragment having $m / z$ 123. This ion of $m / z 123$ losses $-\mathrm{CH}_{2} \mathrm{CH}_{2}$ and produces fragment ion of $m / z 79$, which further fragments to $m / z 78$ by loss of hydrogen.

More intense SRM pair was used as MS quantifier and second most as MS confirming pair. This strategy is in accordance with common practice for SRM-based quantitation on a triple quadrupole which ensures specificity. Use of this approach helps to overcome the matrix effects (Wang et al. 2016). The optimized auto-SRM transitions data of MMS, EMS, IMS and chlorobenzene is provided in supplementary file S2.

In SRM mode, the mass spectrometer is set to scan all SRM transitions simultaneously. The simultaneous scanning of multiple transitions at all the time causes lowering of sensitivity. However in t-SRM mode, the mass spectrometer scans particular transition during a set retention time 


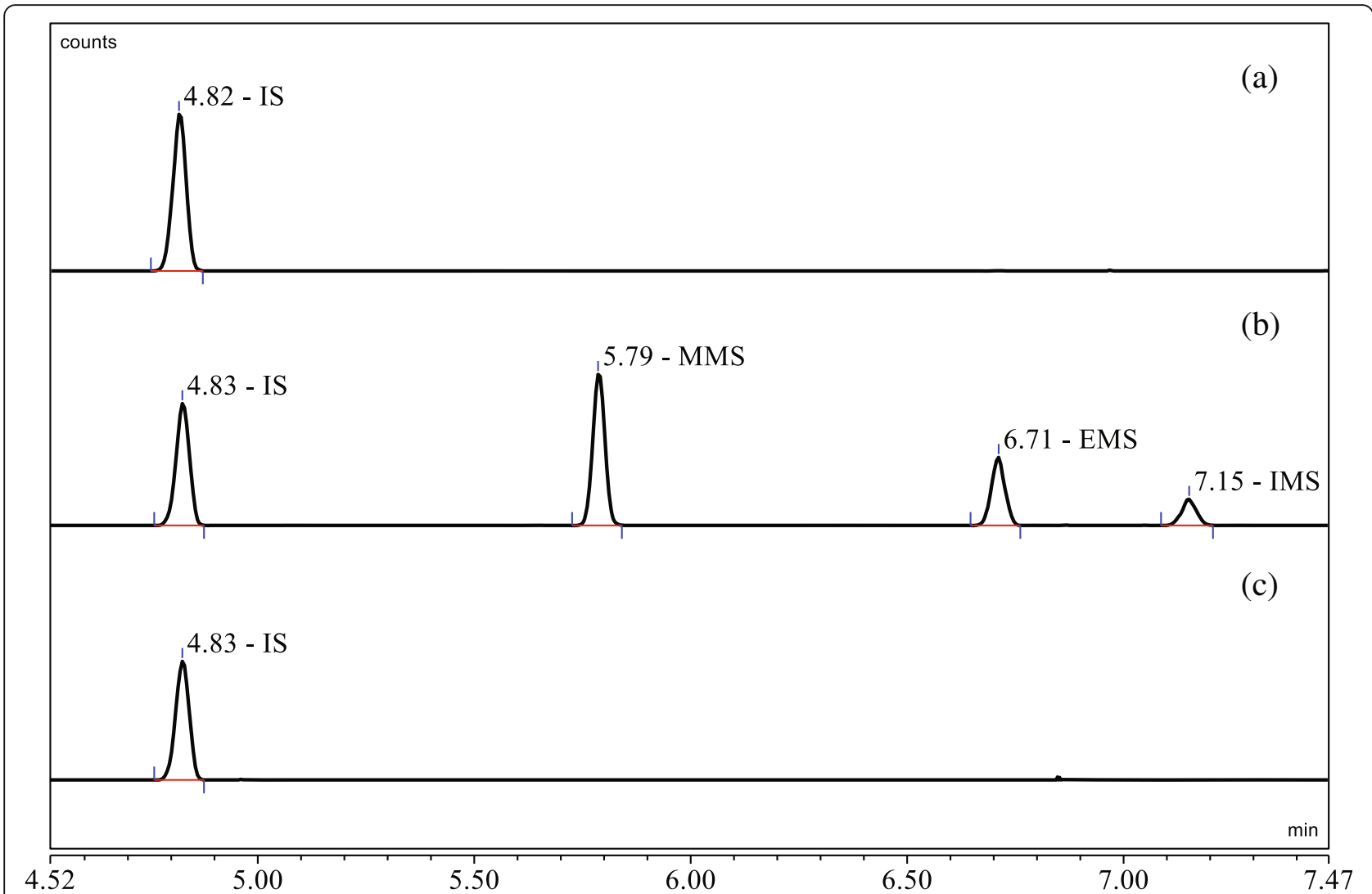

Fig. 3 Representative total ion chromatograms of a extraction solvent with IS, b standard solution, and $\mathbf{c}$ test solution on Rtx-624 column

window, which ultimately effects in increasing the signal to noise ratio.

Overlaid total ion chromatograms of extraction solvent with IS, standard solution, and test solution are shown in Fig. 3. For quantitation, extracted ion chromatograms were processed using the Gaussian smooth integration.

\section{Method validation}

The developed method was specific as there was no interference from the extraction solvent at the retention time as well as mass transition of analytes. The retention times of IS, MMS, EMS and IMS were about 4.8, 5.8, 6.7, and 7.1 minute, respectively. The system was precise with RSD of the peak area ratio of $2.54 \%, 15.54 \%$, and $5.31 \%$ for MMS, EMS, and IMS, respectively.

Because the test batch of ALA did not contain AMs, method precision was determined on the externally spiked solution. The method was precise with RSD of the individual AM content less than $10 \%$ determined on six individual measurements in repeatability and intermediate precision experiments.

The detector response was linear for MMS in the range of 3.1 to $255.8 \mathrm{ng} / \mathrm{mL}$ with regression equation $y$ $=22.333 x+0.0247$ and correlation coefficient of 0.9991 ; EMS in the range of 3.1 to $255.8 \mathrm{ng} / \mathrm{mL}$ with regression equation $y=10.572 x-0.0136$ and correlation coefficient of 0.9986 ; IMS in the range of 10.2 to $255.8 \mathrm{ng} / \mathrm{mL}$ with regression equation $y=5.118 x+0.0148$ and correlation coefficient of 0.9975 . The calibration curves of MMS, EMS and IMS are provided in supplementary file S3.

LOQ of MMS, EMS and IMS were 5, 10, and $20 \mathrm{ng} / \mathrm{g}$ of ALA, respectively. On column LOQ of MMS, EMS, and IMS were $0.01,0.02$, and $0.04 \mathrm{ng}$, respectively. RSD of the peak area ratio at the LOQ was $4.40 \%, 5.44 \%$, and $3.43 \%$ for MMS, EMS, and IMS, respectively. RSD of the peak area ratio at the LOD was 4.64\%, 14.02\%, and $10.70 \%$ for MMS, EMS, and IMS, respectively.

Method was accurate with mean recoveries of MMS, EMS, and IMS were $91.77 \pm 3.09 \%, 93.56 \pm 2.97 \%$, and $97.65 \pm 4.43 \%$, respectively. The developed GC-MS/MS method was found robust as there was no significant effect of the possible variables on the chromatographic performance and system precision. The method validation data is summarized in Table 4.

\section{Advantages and application of the method}

The developed method uses a simple, cost effective LLE sample preparation procedure as compared to reported method like filtration (additional cost of filter), solid phase micro-extraction (high cost of extraction 
Table 4 Method validation summary

\begin{tabular}{llll}
\hline Parameter & MMS & EMS & IMS \\
\hline System precision (peak area ratio RSD, \%) & \multicolumn{1}{c}{2.19} & 1.54 & 5.31 \\
Method precision (RSD, \%) & 1.50 & 1.39 & 4.64 \\
Linearity $(R)$ & 0.99957 & 0.99932 & 0.99877 \\
Mean accuracy $(\%)(n=3)$ & 91.77 & 93.56 & 97.65 \\
LOQ (ng/g) & 5 & 10 & 20 \\
LOQ (Absolute on column, ng) & 0.01 & 0.02 & 0.04 \\
LOD (ng/g) & 2.5 & 5.0 & 10 \\
LOD (absolute on column, ng) & 0.006 & 0.01 & 0.02 \\
Robustness & Peak area ratio (RSD, \%) \\
Flow rate $(+10 \%)$ & 1.83 & 1.39 & 3.96 \\
Flow rate $(-10 \%)$ & 1.74 & 1.55 & 4.81 \\
Column temperature $\left(+2{ }^{\circ} \mathrm{C}\right)$ & 1.93 & 1.77 & 4.39 \\
Column temperature $\left(-2^{\circ} \mathrm{C}\right)$ & 1.88 & 1.63 & 5.11 \\
\hline
\end{tabular}

cartridges), and pre-derivatization (require specific chemical, involve various side reactions, sample matrix gets more complex and overall longer analysis time). In LLE, analytes are extracted from one phase to another phase based on the partitioning of the analytes between two immiscible phases. The LLE also help to produce matrix free test solution for trace analysis, which also prevents the clogging of the injector port and column resulting in consistent response and improved GC column life.

Use of SRM scan function made the method more specific and selective as compared to the SIM. In SIM scan an intensity of the precursor ion is considered for quantification purpose whereas in the SRM scan an intensity of the product ion of the precursor ion is measured to quantify, thus the later mode enhances the specificity and selectivity of the measurement. Overall shorter run time of $<10 \mathrm{~min}$ for the estimation of 3 AMs facilitate high through put screening of the ALA batches in quality control set up.

Based on the therapeutic daily dose and shorter duration of the treatment, acceptable limit for genotoxic impurity in ALA is $40 \mu \mathrm{g} / \mathrm{g}$. The LOQ achieved by the developed method is well below of this acceptable limit. Thus, the developed and validated method is suitable for determination of AMs in the new drug substance ALA. In comparison to the reported methods for other drugs, the developed method is more sensitive, the comparative LOQ data is summarized in Table 5.

The present method could be broadly applied to any other water soluble drug substances, excipients or drug products for determination of AMs. Sensitivity of the method could be further enhanced by modifying the split ratio, injection volume and test solution concentration.

Developed method was applied for the estimation of AMs in pre-clinical and clinical batches of ALA. All these batches of ALA were found to be free from the AMs proving the capability of the purification process adopted to remove these unwanted genotoxic impurities during manufacturing of ALA.

\section{Conclusion}

t-SRM-based GC-MS/MS method successfully developed for estimation of AMs in new drug ALA. Auto-SRM capability was employed to identify the apt precursor ion and product ion pair which could provide maximum sensitivity. LLE technique was engaged to isolate the AMs from the new drug substance ALA. The developed method was highly sensitive with LOQ for MMS, EMS, and IMS as 5, 10, and $20 \mathrm{ng} / \mathrm{g}$ of ALA, which was very important for investigation of genotoxic impurities in new drug substance. The method was fully validated as per the ICH guideline. The method validation results were well within the acceptance limits.

Overall, the described method is simple, convenient, rapid and cost effective. This research demonstrated application of the auto-SRM and t-SRM in detecting trace level of genotoxic impurities using GC-MS/MS during pharmaceutical development.

Table 5 LOQ comparison of MMS, EMS, and IMS with published methods

\begin{tabular}{|c|c|c|c|c|}
\hline \multirow[t]{2}{*}{ Technique } & \multicolumn{3}{|c|}{ LOQ (ng/g) } & \multirow[t]{2}{*}{ Reference } \\
\hline & MMS & EMS & IMS & \\
\hline GC-MS/MS-direct injection & 40 & 30 & 30 & Liu et al. 2019 \\
\hline LC-MS/MS with ESI & 400 & 400 & - & Kakadiya et al. 2011 \\
\hline LC-MS/MS with APCI & 10000 & 10000 & 10000 & Guo et al. 2014 \\
\hline GC-MS-direct injection & 2720 & 2240 & 1920 & Wollein and Schramek 2012 \\
\hline GC-MS-headspace derivatization & 310 & 60 & 150 & Alzaga et al. 2007 \\
\hline GC-MS/MS with LLE & 5 & 10 & 20 & Present work \\
\hline
\end{tabular}




\section{Supplementary information}

Supplementary information accompanies this paper at https://doi.org/10. 1186/s40543-020-00214-w.

\section{Additional file 1: Supplementary file S1. Mass spectrum of} Chlorobenzene (IS), MMS, EMS and IMS with putative fragmentaton pathway.

Additional file 2: Supplementary file S2. Auto-SRM optimization data. Additional file 3: Supplementary file S3. Calibration curves of MMS, EMS and IMS.

\section{Abbreviations}

ALA: Alalevonadifloxacin mesylates; AMs: Alkyl mesylates; GTls: Genotoxic impurities; t-SRM: Time-dependent selected reaction monitoring; GC-MS/ MS: Gas chromatography tandem mass spectrometry; MMS: Methyl methane sulfonate; EMS: Ethyl methane sulfonate; IMS: Isopropyl methane sulfonate; LLE: Liquid-liquid extraction; Auto-SRM: Automatic selective reaction monitoring: DNA: Deoxyribo nucleic acid; ICH: International Conference on Harmonization; TTC: Threshold of toxicological concern; LC-MS/MS: Liquid chromatography tandem mass spectrometry; SIM: Selected ion monitoring; USA: United States of America; DCM: Dichloromethane; IS: Internal standard

\section{Acknowledgements}

Authors thank the management of Wockhardt Limited for their support to conduct this work

\section{Authors' contributions}

Vinod K Ahirrao: Conceptualization, Writing-Original draft, Visualization. Rajiv A Jad hav: Methodology, Investigation. Vipul P Rane: Writing-Review and Editing. Harshal Bhamare: Validation. Ravindra D Yeole: Supervision, Project administration, WritingReview and Editing. All authors read and approved the final manuscript.

\section{Funding}

Expenses for conducting this study was part of the Drug Discovery program budget of Wockhardt Limited.

\section{Availability of data and materials}

All data generated during this study are included in the present manuscript and its supplementary information files.

\section{Ethics approval and consent to participate}

This article does not contain any studies with human participants or animals performed by any of the authors.

\section{Competing interests}

The authors declare that there is no conflict regarding publication of this manuscript.

Received: 10 February 2020 Accepted: 23 April 2020

Published online: 17 June 2020

\section{References}

Alzaga R, Ryan RW, Taylor-Worth K, Lipczynski AM, Szucs R, Sandra P. Generic approach for the determination of residues of alkylating agents in active pharmaceutical ingredients by in situ derivatization-headspace-gas chromatography-mass spectrometry. J Pharm Biomed Anal. 2007;45:472-9. https://doi.org/10.1016/j.jpba.2007.07.017.

An J, Sun M, Bai L, Chen T, Liu DQ, Kord A. A practical derivatization LC/MS approach for determination of trace level alkyl sulfonates and dialkyl sulfates genotoxic impurities in drug substances. J Pharm Biomed Anal. 2008;48: 1006-10. https://doi.org/10.1016/j.jpba.2008.06.019.

Andrew T, Delaney JEJ, Stephen CE, Karine J, Karen TW, Andrew L, Wilfried H, Van R, David PE, Kevin LF, Simon G, Rolf SO, Pat S, Frank D. A detailed study of sulfonate ester formation and solvolysis reaction rates and application toward establishing sulfonate ester control in pharmaceutical manufacturing processes. Org Process Res Dev. 2010;14:999-1007. https://doi.org/10.1021/op900301n.

Chugh R, Lakdavala F, Bhatia A. Safety and pharmacokinetics of multiple ascending doses of WCK 771 and WCK 2349, Abstract: P1268. Amsterdam: 26th Eur Congr Clin Microbiol Infect Dis; 2016.
Chugh R, Lakdavla F, Bhagwat S, Patel LM, Bhatia A. Food effect and absolute bioavailability study of WCK 2349 and WCK 771 in healthy adult human volunteers in U.S., Abstract: A-039, 55th Intersci Conf Antimicrob Agents Chemother., San Diego, CA. Washington, DC: American Society for Microbiology; 2015

Colon I, Richoll SM. Determination of methyl and ethyl esters of methane sulfonic, benzene sulfonic and p-toluene sulfonic acids in active pharmaceutical ingredients by solid-phase micro extraction (SPME) coupled to GC/SIM-MS. J Pharm Biomed Anal. 2005;39:477-85. https://doi.org/10. 1016/j.jpba.2005.04.037.

Dobbeleer I, Gummersbach J, Huebschmann H. Analysis of alkyl phenols using GC-MS/MS and automated SRM development. Thermo Fisher Scientific, Dreieich, Germany Application note: 10407. https://assets.thermofisher.com. Accessed 10 Dec 2018.

Department of Health and Human Services, Food and Drug Administration, Center for Drug Evaluation and Research (CDER). Genotoxic and carcinogenic impurities in drug substances and products: Recommended approaches. Silver Spring; 2008.

Committee for medicinal products for human use (CHMP), European Medicines Agency (EMEA). Guideline on the limits of genotoxic impurities. London: (CPMP/SWP/5199/02, EMEA/CHMP/OWP/251344/2006); 2006.

Guo T, Shi Y, Zheng L, Feng F, Zheng F, Liu W. Rapid and simultaneous determination of sulfonate ester genotoxic impurities in drug substance by liquid chromatography coupled to tandem mass spectrometry: Comparison of different ionization modes. J Chrom A. 2014;1355:73-9. https://doi.org/10. 1016/j.chroma.2014.05.079.

ICH. Q2(R1) Validation of analytical procedures: Text and Methodologies. Geneva: Proceeding of The International Conference on Harmonization; 2005.

ICH. M7(R1) Assessment and Control of DNA Reactive (Mutagenic) Impurities in Pharmaceuticals to Limit Potential Carcinogenic Risk, 2017.

Introducing Auto SRM: MRM Simplicity for High Performance Results. Thermo Fisher Scientific, Dreieich, Germany Application Brief: AB52298_E 05/12S. https://www.analiticaweb.com. Accessed 20 Mar 2020.

Kakadiya PR, Chandrashekhar TG, Ganguly S, Singh DK, Singh V. Low leve Determinations of methyl methanesulfonate and ethyl methanesulfonate impurities in emtricitabine active pharmaceutical ingredient by LC/MS/MS using electrospray ionization. Anal Chem Insights. 2011;6:21-8. https://doi. org/10.4137/ACI.S6471.

Liu X, Zhang W, Han H, Sun L, Chen D. Trace determination of mutagenic alkyl toluene sulfonate impurities via derivatization headspace-GC/MS in an active pharmaceutical ingredient of a candidate drug. J Pharm Biomed Anal. 2018; 155:104-8. https://doi.org/10.1016/j.jpba.2018.03.054.

Liu Z, Fan H, Zhou Y, Qian X, Tu J, Chen B, Duan G. Development and validation of a sensitive method for alkyl sulfonate genotoxic impurities determination in drug substances using gas chromatography coupled to triple quadrupole mass spectrometry. J Pharm Biomed Anal. 2019;168:23-9. https://doi.org/10. 1016/j.jpba.2018.12.044.

Mason JW, Chugh R, Patel A, Gutte R, Bhatia A. Electrocardiographic effects of a supratherapeutic dose of WCK 2349, a benzoquinolizine fluoroquinolone. Clin Trans Sci. 2019;12:47-52. https://doi.org/10.1111/cts.12594.

Muller L, Mauthe RJ, Riley CM, Andino MM, Antonis DD, Beels C, DeGeorge J, De Knaep AGM, Ellison D, Fagerland JA, Frank R, Fritschel B, Galloway S, Harpur E, Humfrey CDN, Jacks AS, Jagota N, Mackinnon J, Mohan G, Ness DK, Donovan MRO, Smith MD, Vudathala G, Yotti L. A rationale for determining, testing, and controlling specific impurities in pharmaceuticals that possess potential for genotoxicity. Regul Toxicol Pharmacol. 2006;44:198-211. https:// doi.org/10.1016/j.yrtph.2005.12.001.

Niu J, Ivaturi V, Niu J, Gobburu J, Chugh R, Bhatia A. Pharmacokinetics of levonadifloxacin administered as intravenous WCK 771 and oral WCK 2349 in healthy Indian male adults, Abstract: A-032, 55th IntersciM Conf Antimicrob Agents Chemother., San Diego, CA. Washington, DC: American Society for Microbiology; 2015.

Patel MV, Desai VN, Deshpande PK, Yeole RD, Kale RP, Prodrugs of benzoquinolizine 2-carboxylic acid. US Patent no. US7868173B2, ;2012.

Polarity index of solvents. https://macro.Isu.edu/howto/solvents/Polarity\%20index. htm. Accessed 20 Mar 2020.

Ramakrishna K, Raman NWSS, Narayana Rao KMV, Prasad AVSS, Subhaschander Reddy K. Development and validation of GC-MS method for the determination of methyl methanesulfonate and ethyl methanesulfonate in imatinib mesylate. J Pharm Biomed Anal. 2008:46:780-3. https://doi.org/10. 1016/j.jpba.2007.11.013. 
Ramana NWSS, Prasad AVSS, Ratnakar Reddy K, Ramakrishna K. Determination of genotoxic alkyl methane sulfonates and alkyl para toluene sulfonates in lamivudine using hyphenated techniques. J Pharm Anal. 2012;2:314-8. https://doi.org/10.1016/j.jpha.2012.03.003.

Rodvold AK, Gotfried MH, Chugh R, Gupta M, Yeole R, Patel A, Bhatia A. Intrapulmonary pharmacokinetics of levonadifloxacin following oral administration of alalevonadifloxacin to healthy adult subjects. Antimicrob Agents Chemother. 2018;62:e02297-17. https://doi.org/10. 1128/AAC.02297-17.

Sitaram C, Rupakula RB, Reddy BN, Sastry CSP. Determination of alkyl methane sulfonates in doxazosin, mesylate by gas chromatography-mass spectrometer. Indian J Pharm Sci. 2011;73:107-10. https://doi.org/10.4103/ 0250-474X.89769.

Snodin DJ. Elusive impurities - evidence versus hypothesis. Technical and regulatory update on alkyl sulfonates in sulfonic-acid salts. Org Process Res Dev. 2019;23:695-710. https://doi.org/10.1021/acs.oprd.8b00397.

Snodin DJ, Teasdale A. Mutagenic alkyl-sulfonate impurities in sulfonic-acid salts: reviewing the evidence and challenging regulatory perceptions. Org Process Res Dev. 2015;19:1465-85. https://doi.org/10.1021/op500397h.

Teasdale A. Genotoxic Impurities: Strategies for Identification and Control. Hoboken: Wiley; 2011.

Wang $\mathrm{EH}$, Combe PC, Schug KA. Multiple reaction monitoring for direct quantitation of intact proteins using a triple quadrupole mass spectrometer J Am Soc Mass Spectrom. 2016;27:886-96.

Wollein U, Schramek N. Simultaneous determination of alkyl mesilates and alkyl besilates in finished drug products by direct injection GC/MS. Eur J Pharm Sci. 2012;45:201-4. https://doi.org/10.1016/j.ejps.2011.11.008.

\section{Publisher's Note}

Springer Nature remains neutral with regard to jurisdictional claims in published maps and institutional affiliations.

\section{Submit your manuscript to a SpringerOpen ${ }^{\circ}$ journal and benefit from:}

- Convenient online submission

- Rigorous peer review

- Open access: articles freely available online

- High visibility within the field

- Retaining the copyright to your article

Submit your next manuscript at $\boldsymbol{\triangleright}$ springeropen.com 